\title{
Las Influencias Francesas en la Poesía Hispanoamericana
}

Este estudio fué escrito en francés para ser presentado en el "Congreso de las Naciones Americanas", reunido en París por iniciativa del "Institut des Etudes Américaines". Al traducirlo al español, el autor ha agregado algunas notas complementarias.

\section{I}

LOS GRANDES MOVIMIENTOS LITERARIOS

EN LA AMERICA ESPAÑOLA Y LAS

INFLUENCIAS EXTRANJERAS

N la literatura de cada país de la América Española pue-
gen encontrarse modalidades y aun particularidades re-
gionales. Desde este punto de vista, así como desde el punto
de vista histórico y político, se puede hablar de una literatura
propia en cada una de las repúblicas americanas, separada-
mente de la literatura española, del mismo modo que se habla
de una literatura de los Estados Unidos de América separa-
damente de la literatura inglesa y de una literatura brasileña
separadamente de la literatura portuguesa.
Ahora bien: en su conjunto, las literaturas de los dife-
rentes países de la América Española han mantenido siem- 
pre un ritmo uniforme que se caracteriza por grandes movimientos de extensión continental, sea en el orden de las ideas, sea en el orden de la expresión poética o de la forma literaria. Con mayor exactitud aún se puede hablar, por lo tanto, aun desde un punto de vista puramente intelectual, de una literatura hispanoamericana, es decir, de una rama importante y más o menos independiente de la literatura española. Podría aplicarse al estudio de la literatura hispanoamericana el método adoptado por Georg Brandes para estudiar las grandes corrientes literarias del siglo $X I X$ en la Europa occidental.

En la mayor parte de los casos, los, grandes movimientos que se produjeron de modo simultáneo en todo el continente americano se encuentran ligados a un problema de influencias. Naturalmente, la influencia preponderante ha sido siempre la de España, que es casi exclusiva durante la época colonial. Pero aun en la época colonial ciertas particularidades regionales de la literatura hispanoamericana resultan ya evidentes, y el caso del mexicano Juan Ruiz de Alarcón, que llevó al teatro español un espíritu sutil y mesurado, puede servir para comprobarlo de modo elocuente. (1) Llega un día en que las influencias hispanoamericanas se hacen sentir en la literatura de España, como en justa reciprocidad, (2) puesto que España ha conservado siempre su ascendiente espiritual en la literatura hispanoamericana.

$E_{S}$, pues, al través de España como la literatura hispanoamericana recibe en un principio las influencias extranjeras. Más tarde habrá influencias recibidas en la América Española al mismo tiempo que en España; y en fin, habrá también influencias que se manifestarán en el continente americano antes de haberse manifestado en España, y que la América introducirá en España.

La tradición clásica en la literatura hispanoamericana nos llegó al través de España. Bien es cierto que España, cuando la conquista de América no había terminado aún, estableció una Universidad en Santo Domingo (en 1538), y otras, apenas al mediar el siglo XVI, en Lima y en México.

Uno de los grandes movimientos literarios del continente es el regionalismo americano, el "americanismo literario", 
para emplear la frase más usual. Ese movimiento se inició a orillas del Río de la Plata y tuvo eco dilatado en toda la América Española. No es tarea fácil la de encontrar influencias extranjeras en un movimiento que aspiró a revelar todo lo que hay de interesante en el escenario del Nuevo Mundo. Las encontraremos, sin embargo, en una rama de ese movimiento: la literatura de evocación indígena, que produjo obras como Cumandá, del ecuatoriano Juan León Mera, Celiar, del uruguayo Alejandro Magariños Cervantes, Enriquillo, del dominicano Manuel de Jesús Galván, y Tabaré, del uruguayo Juan Zorrilla de San Martín. (3) A veces encontramos en esa literatura un eco de Chateaubriand, que popularizó los temas indigenas. Es verdad que los indios de Chateaubriand eran los de la América del Norte, y no de la del centro ni de la del sur, y que él evocaba tradiciones y medios diferentes; pero en más de una novela o poema indígena de la América Española se encuentran mujeres que tienen estrecho parentesco con Atala. El colombiano José Fernández Madrid tomó como tema a Atala para escribir un drama. Y al hablar de una de las más bellas novelas americanas, Maria, del colombiano Jorge Isaacs, su compatriota Antonio Gómez Restrepo dice que la heroína de esa novela es una hermana de Atala y de Virginia. $Y$ es que, sin lugar a dudas, Bernardin de Saint-Pierre tuvo también en la América Española una influencia semejante, principalmente como pintor de la naturaleza.

Pero ante todo se leía a Chateaubriand - cuya Atala fué traducida primero en Hispanoamérica que en España-, y su influencia sobre el gran poeta cubano José María Heredia, cantor del Niágara y primo hermano del autor de Los Trofeos, es indiscutible. También se leía en la América Española, en los comienzos del siglo XIX, a Rousseau y Montesquieu, a Voltaire y Diderot, y la influencia que ellos ejercieron sobre las ideas políticas y sociales - sobre todo la de Rousseaufué extraordinaria, como lo fué, por otra parte, sobre el liberalismo español que acababa de nacer. 


\section{LA EPOCA ROMANTICA}

Las influencias francesas se manifiestan de modo directo en la poesía hispanoamericana, por primera vez, al mismo tiempo que en España, con el movimiento romántico. No se trata de una influencia recibida al través de España, sino al mismo tiempo que en España.

Aún más: en América hubo, independientemente de España, precursores del romanticismo. El más notable fué Heredia, el cantor del Niágara, lírico de gran fuerza, que era romántico por temperamento. Además, Heredia cultivó el teatro y adaptó al idioma español obras de Ducis, Voltaire, Jouy y Marie-Joseph Chénier.

El romanticismo encontró ya trazado su camino en la América Española. Apenas habían transcurrido algunos años, después de la batalla de Hernani, cuando un acontecimiento semejante se produjo en La Habana: el estreno de Don Pedro de Castilla, del dominicano Francisco Javier Foxá - uno de los primeros dramas románticos de autor hispanoamericano-, terminó con riñas y tumultos. La obra de Foxá no respetaba las tres unidades y hacía revivir en cierto modo la tradición del teatro español de los siglos de oro, pero el público se rebeló contra esa resurrección que se le ofrecía a título de innovación. $\mathrm{Y}$ fueron los jóvenes románticos los que tomaron la ofensiva, pues un espectador inconforme recibió tal tunda de bastonazos que murió algunos días después.

Este fenómeno, aunque puramente local, es un síntoma. El romanticismo brindará estímulo a las pasiones febriles y a la agitación del espíritu en los jóvenes hispanoamericanos. Ciertamente, la exageración romántica no será un privilegio americano, pero habrá quienes lloren y sueñen, quienes maldigan, $\mathrm{y}$ acaso habrá también quienes blasfemen. Toda una literatura gritona y lacrimosa va a nacer junto a manifestaciones más puras y delicadas en las cuales será posible reconocer la influencia de tres grandes poetas franceses: Lamartine, Víctor Hugo y Musset. En 1833 se les traducía e 
imitaba en Montevideo, donde el uruguayo Lamas y el argentino Cané publicaban El Iniciador, publicación cuyo nombre era un programa. El contagio se extendió a toda la América Española. Y ya en 1841 el humanista Andrés Bello se dedicaba a traducir, de modo que casi raya en la perfección, "La oración por todos", "Los fantasmas", "A Olympio", "Moisés salvado de las aguas" y "Los duendes", de Víctor Hugo. El chileno Guillermo Matta hizo otra traducción de "La oración por todos". La cubana Gertrudis Gómez de Avellaneda tradujo también "Los duendes"; largo tiempo después fué el centroamericano Domingo Estrada quien tradujo en versos españoles ese mismo poema, como lo ha intentado en nuestros días el venezolano González Rincones. Bello tradujo también fragmentos de Byron, que apasionó a muchos espíritus hispanoamericanos, y la influencia de Byron se acentuó mucho en Chile. Igualmente en el Río de la Plata con Esteban Echeverría y en México con Roa Bárcena.

Muchos otros poetas tradujeron a Víctor Hugo: el chileno Rafael Minvielle trasladó al español el drama Hernani; y otros hicieron lo mismo con diversas composiciones poéticas: el peruano Ricardo Palma ("La conciencia"), el cubano Rafael María Mendive ("Los crucificados", "El pueblo", y muchas más), el venezolano José Antonio Calcaño ("Religión"), el dominicano Apolinar Tejera ("Extasis"), el centroamericano Francisco Gavidia ("Stella"). La influencia de Víctor Hugo fué preponderante durante más de medio siglo: la encontramos mezclada con otras, en muchos poetas, proteiforme y constante. Hay dos poetas en los cuales esa influencia se confundía con su propia personalidad: el argentino Olegario Víctor Andrade (que intercaló en su nombre el de Victor, como homenaje al maestro), uno de los más brillantes poetas hispanoamericanos, y el cubano Rafael María Mendive, que supo dar a su verso sonoridades musicales. La influencia de Víctor Hugo sobrevivió durante largo tiempo, casi hasta nuestros días. Se encuentra en la obra de juventud. de muchos poetas de alta significación en el modernismo hispanoamericano, la nueva escuela que en cierto sentido fué algo así como un eco del simbolismo francés: así en el centroamericano Rubén Darío; en el mexicano, Salvador Díaz Mi- 
rón; en el argentino Leopoldo Lugones; en el peruano José Santos Chocano. i $Y$ todavía! Nuestro siglo tenía ocho años, y en Colombia un joven que apenas contaba diez y seis, Angel María Céspedes, triunfaba en un concurso poético con un poema, "La juventud del sol", concepción imaginativa llena de fuego y de sonoridad verbal, afortunada evocación de la manera hugoniana.

Igual ocurrió con Musset. Se le tradujo, pero sobre todo se le imitó. El poema "Fidelia", del cubano Juan Clemente Zenea, es tan desgarrador como "Lucía", que por otra parte el mismo Zenea tradujo de manera admirable. Muchos otros poetas sufrieron la influencia de Musset: el mexicano Manuel Puga y Acal, que también lo tradujo; el chileno Guillermo Blest Gana, autor de una paráfrasis de "La noche de diciembre", que intituló, de acuerdo con la diferencia de estaciones en otro hemisferio, "La noche de mayo". El dominicano Fabio Fiallo, traductor de "La andaluza", "El Rhin alemán" y "iAcuérdate de mí!", encontró inspiración para una de sus más bellas composiciones en la "Canción de Fortunio", de la cual hay dos bellas traducciones: una del mexicano Manuel Gutiérrez Nájera y otra del dominicano Enrique Henríquez. En fin, la influencia de Musset subsistía en el momento mismo en que se anunciaba una nueva tendencia: uno de los precursores del modernismo, Gutiérrez Nájera, se inspiró en "Lucía" (al igual que lo había hecho Zenea), para escribir un poema emocionante: "La serenata de Schubert".

La influencia de Lamartine fué de más corta duración, pero fué profunda. Lamartine no tuvo gran número de traductores: la dominicana Josefa Antonia Perdomo ("Otoño"), el cubano Rafael María Merchán ("Fragmentos de Jocelyn"), el colombiano Antonio José Restrepo (que tradujo con fidelidad y elegancia "El crucifijo"), y algunos más. Se le imitó menos, pero dos generaciones hispanoamericanas se sintieron deslumbradas por su sensibilidad: así los peruanos Luis Benjamín Cisneros y Carlos Augusto Salaverry, el colombiano José María Samper, los chilenos Martín José Rivas y Víctor Torres Arce (que compuso una especie de paráfrasis de "El lago"), el mexicano Fernando Calderón, el centroamericano Eduardo Hall. Su personalidad también era motivo de 
admiración. Y él aprovechó más de una vez la ocasión de corresponder a los frecuentes homenajes que recibía del Nuevo Mundo: así, escribió un prefacio para un volumen de versos del colombiano José María Torres Caicedo.

¿Otras influencias francesas? Las hay, sin duda, pero no son de carácter muy general en la poesía hispanoamericana. Alfred de Vigny inspiró quizás un drama del peruano Salaverry y poemas del chileno Hermógenes Irisarri. Casimir Delavigne fué traducido por el colombiano Fernández Madrid. Pero son casos aislados e individuales, como ciertas imitaciones de Jean-Baptiste Rousseau por el cubano Ignacio Valdés Machuca y la traducción de los "Yambos" de Barbier por otro cubano: Aniceto Valdivia. (4)

Las influencias románticas francesas se entremezclan, en la segunda mitad del siglo XIX, con otras influencias extranjeras, sobre todo con la de Edgar Poe, la de Heine y la de Manzoni. El espíritu de Poe quedó incorporado a diversas manifestaciones poéticas en la literatura hispanoamericana, pero es raro encontrar imitaciones o evocaciones directas de ese espíritu, como ocurre en "Nevermore", del dominicano Enrique Henríquez. (5) La influencia de Poe se revela casi siempre por matices o detalles que pueden parecer secundarios, pero en todo caso Poe es uno de los poetas que más se han traducido al español en América. Hay cerca de una docena de traducciones de "El cuervo": la del venezolano Juan Antonio Pérez Bonalde es la más antigua y la más inspirada, pero hay algunas más que se deben a los colombianos Carlos Arturo Torres e Isaías Gamboa, al centroamericano Guillermo F. Hall, a los mexicanos Ignacio Mariscal y Ricardo Gómez Robelo - y omito otras varias-, hasta llegar a la del argentino Carlos Obligado, que es la más reciente y la más fiel. También han sido muy traducidas "Las campanas", esa maravilla prosódica de la lengua inglesa: el centroamericano Domingo Estrada lo hizo con arte. En suma, toda la obra poética de Poe ha sido traducida, aun de modo integral por un solo poeta, como lo ha hecho Carlos Obligado. La influencia de Heine, traducido por el venezolano Pérez Bonalde, por los cubanos Antonio y Francisco Sellén y por el peruano Ricardo Palma, se encuentra casi siempre mez- 
clada a la del poeta español Bécquer. En cuanto a Manzoni, traducciones múltiples de su oda "El cinco de mayo" (6) explican la adopción de una combinación métrica (en la cual abundan los esdrújulos), semejante a las estrofas de esa obra maestra. No sé si fué José Heriberto García de Quevedo el primero en emplear esa combinación en español, pero varios poetas la adoptaron, entre otros el dominicano José Joaquín Pérez.

Debo hacer mención de otra influencia italiana muy difundida en la América Española: la de Leopardi, que ha tenido excelentes traductores como el colombiano Antonio Gómez Restrepo.

\section{III}

\section{PARNASISMO, SIMBOLISMO, MODERNISMO}

Cuando la estrella del romanticismo empieza a palidecer, una nueva tendencia se abre camino en la poesía hispanoamericana. Esa tendencia, que recibió el nombre un tanto vago de "modernismo", nació de la influencia directa de dos movimientos poéticos franceses: el Parnaso y el simbolismo. (7) El movimiento modernista nació en el continente americano, y de América llegó después a España.

La influencia de los parnasianos y la de los simbolistas y decadentes se combinaron en la América Española para declarar la guerra a la vulgaridad, para predicar el culto de la perfección en la forma poética, para evocar la belleza y la gracia de tiempos ya idos - sea la inmortal y fecunda tradición helénica, sea la frivolidad espiritual del siglo XVIII-, $y$, en fin, para traducir las inquietudes y las angustias del espíritu contemporáneo.

El más ilustre precursor del modernismo hispanoamericano fué el mexicano Manuel Gutiérrez Nájera. En su obra personal puede seguirse el proceso de las principales influencias que prevalecieron durante el período de transición entre el romanticismo y las iuevas tendencias. Sufrió, como todos los hispanoamericanos, influencias españolas, principalmente 
la de Bécquer y la de Campoamor, pero, además, nos dice su compatriota Carlos González Peña, sintió "el influjo de todos los poetas franceses, a partir de la generación romántica hasta los contemporáneos; desde Hugo, Lamartine y Musset, hasta Richepin, Rollinat y Verlaine, pasando por Gautier, Baudelaire y Coppée". (8)

Otro de los iniciadores del modernismo, el cubano José Martí -que al mismo tiempo fué apóstol de la libertad-, se significó por la novedad de su prosa, pero difícilmente podríamos encontrar en sus versos, tan originales e inspirados, influencias directas de las nuevas escuelas francesas, que él conocía bien. Un fenómeno semejante es el que puede observarse en el colombiano José Asunción Silva: encontraremos en su obra el recuerdo patente de Edgar Poe y de algunos poetas españoles, como Bécquer y Bartrina, más que el de los poetas franceses de su tiempo, que él había leído con sumo interés y había dado a conocer a los jóvenes escritores de su país. (9)

La figura central del movimiento modernista fué el centroamericano Rubén Darío. Manejó con raro virtuosismo la lengua española, pero su inspiración venía de Francia. No sin razón el escritor español Juan Valera lo acusó de "galicismo mental". Revolucionó la métrica española, pero a veces sus innovaciones eran resurrecciones de antiguas combinaciones rítmicas, algunas de pura cepa clásica, caídas en desuso. En la primera etapa del movimiento publicó un tomo de ensayos críticos, Los raros, mediante el cual difundió en América algunos nombres de autores franceses contemporáneos que prefería: Verlaine, Moréas, Lautréamont, Richepin, Tailhade... En su obra poética, vasta y excepcional, no es difícil señalar, en muchos casos de manera concreta, ciertas influencias: Banville, en algunos frescos funambulescos; Gautier, en la "Sinfonía en gris mayor"; Rimbaud, en "Heraldos"; Leconte de Lisle y José María de Heredia, en evocaciones frecuentes de Ia Grecia antigua; Barbey d'Aurevilly en "Cosas del Cid"; y aún Catulle Mendès y Armand Silvestre en algunas producciones de juventud; pero, ante todo, Verlaine, con el cual tenía fuertes afinidades de temperamento. Consagró a la memoria de Verlaine aquellos versos armoniosos y emotivos: 
Padre y maestro mágico, liróforo celeste, que al instrumento olímpico y a la siringa agreste diste tu acento encantador.

¡Panida! Pan tú mismo, que coros condujiste hacia el prolíleo sacro que amaba tu alma triste, al son del sistro y del tambor.

'Otro de los iniciadores del modernismo fué el cubano Julián del Casal. En él, de igual suerte que en Rubén Darío, las influencias de parnasianos, simbolistas y decadentes coinciden y se combinan: Heredia, en los sonetos de "Mi museo ideal" y "Hércules y las Estinfálidas"; Leconte de Lisle, en "El camino de Damasco"; Verlaine, en "Páginas de vida"; y un tanto Samain en "La cólera del Infante". Se encuentra también, aunque más diluída, en efectos de color y sonido, la de Gautier; e igualmente hay en Casal un eco de Baudelaire, en algunos cuadros sombríos y trágicos. Baudelaire reaparece a menudo en la obra de los modernistas, junto a otras influencias francesas de la época, entre las cuales puede encontrarse la de las "Cantilenas" de Jean Moréas, autor también grato a Casal.

Se ha querido reivindicar el dictado de parnasianos hispanoamericanos en favor de algunos poetas anteriores al movimiento modernista: tal es el caso del venezolano Jacinto Gutiérrez Coll; pero nada podría justificar ese calificativo. Gutiérrez Coll no hizo más que apartarse de las exageraciones románticas de última hora, y cuitivó una expresión poética más serena y refinada, pero aún así siguió siendo romántico. Cuando más podría definírsele como un poeta de transición.

Los verdaderos parnasianos de la América Española vienen un poco más tarde, después de Casal. El más ilustre es el colombiano Guiliermo Valencia, en el cual encontramos el mismo soplo armonioso de Leconte de Lisle (baste citar "Cigüeñas blancas", "Los camellos" y "Palemón el estilita"). Es también a Leconte de Lisle a quien se encuentra ligada la brillante personalidad del boliviano Ricardo Jaimes Frey. re, con su Castalia bárbara. Puede decirse que, aunque en menor grado, Leconte de Lisle tuvo influjo sobre el venezo- 
lano Manuel Pimentel Coronel ("Los paladines") y en otros poetas del continente americano.

Otros sufrieron la influencia de Heredia, que tuvo en la América Española más de cincuenta traductores diferentes. Al colombiano Ismael Enrique Arciniegas se debe una traducción integral de los sonetos de Los trofeos, (10) y yo he tenido la audacia de hacer otro tanto, agregando los últimos sonetos que Heredia dejó escritos para intercalarlos en su famoso libro. La mayor parte de los traductores de Heredia en la América Española son colombianos (cerca de veinte). No es por eso sorprendente encontrar en Colombia buen número de poetas contemporáneos que sufrieron la influencia más o menos directa de los parnasianos franceses, y que han sobresalido en el arte de hacer un bello soneto: Víctor M. Londoño, (11) Miguel Rasch Isla, José Umaña Bernal y aun. José Eustasio Rivera, que supo pintar con sorprendente originalidad los paisajes y misterios de las selvas y las montañas de su país, y Leopoldo de la Rosa, en quien se advierten. a la vez otras influencias de carácter diferente.

La influencia de Heredia se encuentra difundida a lo largo del movimiento modernista: así en toda la obra del argentino Leopoldo Díaz (Las sombras de Hellas, Atlántida conquistada). También aparece en la obra de madurez del peruano José Santos Chocano, que escribió un bello poema para dedicar a Heredia su libro Alma América, sin que, a la postre, esa dedicatoria fuera insertada en el volumen. Chocano no imitó, salvo alguna excepción, al Heredia de los sonetos, sino al Heredia de Los conquistadores del oro, ese vasto monumento, epopeya inacabada de la conquista del Perú.

La influencia parnasiana se advierte también, aunque diluída, en algunos poetas del grupo modernista mexicano, a comienzos del presente siglo: José Juan Tablada, Efrén Rebolledo, Rafael López, Rubén M. Campos, y muchos más.

¿Principales influencias simbolistas? Ante todo, Verlaine, que ha tenido tan notables traductores: el colombiano Guillermo Valencia, el panameño Darío Herrexa, los mexicanos Balbino Dávalos y Enrique González Martínez, (12) el dominicano Gastón F. Deligne, y otros muchos. Verlaine influ- 
yó sobre el modernismo hispanoamericano al través de Rubén Darío, y también al través de Amado Nervo, místico soñador y delicado; pero lo encontramos a cada instante, principalmente en el uruguayo Julio Herrera Reissig (Las pascuas del tiempo) y en el chileno Francisco Contreras (Esmaltes).

Después de Verlaine, Samain. Dejemos a un lado sus traductores, que son numerosos, para apreciar solamente los poetas que revelan su influencia: en Colombia, Eduardo Castillo, que a la vez nos trae algunos ecos de Verlaine y de Rimbaud; en el Perú, José María Eguren, Enrique A. Carrillo, Adán Espinosa Saldaña y Alberto Ureta, que a veces muestra preferencia por Francis Jammes (13) y Paul Fort; en Argentina, el gran poeta Leopoldo Lugones; en el Uruguay, Julio Herrera Reissig. Y volvemos a encontrar algunos rasgos del Samain de la última época, el que cantaba

des airs simples, appris le soir dans les faubourgs,

en el argentino Evaristo Carriego, cantor de-la vida del arrabal bonaerense. (14)

La ironía de Laforgue encontró también eco en la América Española. El más bello reflejo de las melancolías Iunares de Laforgue es el Lunario sentimental de Lugones. Pero junto a Laforgue encontraremos a menudo al Conde de Lautréamont, tal como ocurre en los uruguayos Roberto de las Carreras y Julio Herrera Reissig.

La influencia de Rimbaud se encuentra más bien en algunos detalles aislados, como la asociación de las ideas y los sonidos con los colores.

A las influencias antes señaladas, que son de carâcter más general, pueden agregarse otras de poetas francesas contemporáneos, desde Mallarmé, traducido en veces por el argentino Leopoldo Díaz, por el colombiano Guillermo Valencia y por los mexicanos Rafael Lozano y Alfonso Reyes (que tiene con Mallarmé cierta afinidad de espíritu poético), hasta llegar a Paul Valéry, cuyo "Cementerio marino" ha sido objeto de una traducción admirable por el cubano Mariano Brull. El mexicano Rafael Lozano (traductor de "La siesta del fauno", de Mallarmé) ha vertido al castellano otro poe- 
ma de Valéry: "El segundo Narciso". Volvemos a encontrar a Valéry en la obra del colombiano Otto de Greiff.

La huella de algunos poetas belgas, como Maeterlinck, Redenbach y Verhaeren, no es rara. Se advierte, entre otros, en el mexicano Enrique González Martínez, que llegó a tiempo para predicar una nueva tendencia ideológica: "torcerle el cuello al cisne", símbolo de belleza elegante e inútil, es decir, abandonar la poesía cuando es tan sólo un bello entretenimiento espiritual, y hacerla revivir para magnificar nuestra sed de ideal y de sabiduría.

\section{IV}

\section{EL MOMENTO ACTUAL}

Después del modernismo, que desempeñó una misión necesaria en un momento dado de la evolución literaria hispanoamericana, nuevas tendencias se manifiestan. Son las tendencias de vanguardia. ¿Encontraremos dentro de esas tendencias las influencias francesas, de manera tan precisa como en la época del simbolismo?

El caso no es el mismo. Sería difícil señalar hoy la influencia directa y personal de un autor determinado. La élite juvenil de la América Española ha leído y lee con avidez muchos autores de significación diferente: Apollinaire, Giraudoux, Tristan Tzara, Reverdy, Blaise Cendrars, Montherlant, Morand, André Breton, Philippe Soupault, Valery Larbaud, Ivan Goll, y otros más; pero, ¿se siguen sus huellas y se les imita como sucedió un día con Verlaine o con Samain? Me parece que no. Cuando más, en algunos iniciadores del movimiento actual en Hispanoamérica, como el mexicano Jaime Torres Bodet -que comienza a ser considerado como "un clásico de vanguardia", sin que esto sea una paradoja-, podríamos apreciar tal o cual semejanza con Apollinaire, Giraudoux o Cocteau.

¿Podría decirse lo mismo respecto a los peruanos Alberto Guillén y Alberto Hidalgo, los mexicanos Genaro Estrada, 
Xavier Villaurrutia, Carlos Pellicer y Manuel Maples Arce, el dominicano Domingo Moreno Jimenes, los uruguayos Julio Raúl Mendilaharsu e Ildefonso Pereda Valdés, los argentinos Jorge Luis Borges, Norah Lange y Oliverio Girondo, para no citar más que algunos nombres al azar?

El movimiento de vanguardia hispanoamericano se ha enriquecido en estos últimos tiempos con la revelación de algunas personalidades fuertes e independientes, de gran pujanza, como el chileno Pablo Neruda y el peruano César Vallejo.

Quizás más tarde, cuando el tiempo nos permita ver el fenómeno a mayor distancia, será posible precisar con más exactitud ciertas influencias del momento actual en el movimiento hispanoamericano, pero esas influencias no son exclusivamente francesas.

Para terminar esta exposición somera -que no tiene otro objeto que el de facilitar. una información sintética sobre un tema que merece detenido estudio-, debo hacer mención de los hispanoamericanos que han adoptado la lengua francesa como medio de expresión y de ese modo se han incorporado a la literatura francesa. El ejemplo más ilustre es el de José María de Heredia, nacido en Cuba, descendiente de los viejos conquistadores españoles. Pero cabe citar también a otros cubanos: Augusto de Armas, Cornélius Price, Armand Godoy; un peruano: della Rocea de Vergallo; un colombiano: Alfredo de Bengoechea; un uruguayo: Alvaro Guillot $\mathrm{Mu}-$ ñoz; un argentino: José María Cantilo; un boliviano: Adolfo Costa du Rels; un chileno: Vicente Huidobro; un dominicano: Andrejulio Aybar. ¿El propio Rubén Darío, no escribió en francés una "Oda a la Francia"? En todos o casi todos estos casos se trata de una literatura de emigrados, porque es la permanencia en Francia lo que decidió a esos poetas a adoptar la lengua francesa. Pero en Argentina podemos encontrar algunos ejemplos más de escritores y poetas que, aun antes de haber visitado a Francia, han escrito bellamente en francés: baste citar el nombre de Delfina Bunge de Gálvez.

En la América Española se mantiene vivo el culto de la 
lengua francesa: testimonio elocuente del interés constante con que seguimos el movimiento de las ideas en Francia.

\section{Max Henríquez Ureña.} xico, 1913.

(1).-V. Juan Ruiz de Alarcón, por Pedro Henríquez Ureña, Mé-

(2).-He desarrollado esta tesis en mi libro El retorno de los galeones, Madrid, 1930.

(3).-Magariños Cervantes, autor del poema Celiar, escribió la novela Caramurí, de asunto indígena, que tiene como antecedente un poema brasileño de igual nombre, obra de Fray José de Santa Rita Durao en el siglo XVIII. La literatura de tema indígena alcanzó gran boga a mediados del pasado siglo: a las obras arriba mencionadas pueden agregarse otras muchas, entre ellas, para mencionar siquiera algunas, las obras poéticas Fantasias indígenas, de José Joaquín Pérez, Anacaona, de Salomé Ureña de Henriquez, Guarocuya, de Federico Henríquez y Carvajal (los tres autores son dominicanos); y la Profecía de Guatimoc, del mexicano Rodríguez Galván; los dramas El Charria, del uruguayo Pedro P. Bermúdez, Atabualpa, del peruano Carlos Augusto Salaverry, Lautaro, del chileno Camilo Enríquez, Iguaniona, del dominicano Javier Angulo Guridi; y novelas como Guatimozin, de la cubana Gertrudis Gómez de Avellaneda, y otras muchas cuya relación puede verse en La novela indianista en Hispano-América, por Concha Meléndez (1934).

(4).-No sólo los más conocidos poetas franceses encontraron traductores en la América Española. Aun en época posterior menudean las versiones de poetas de menor significación: así ocurre con Paul Deroulede, uno de cuyos Chants du Paysan ("El agua") fué vertido al castellano, de modo armonioso, por el dominicano Federico Henríquez y Carvajal, y con Jean Aicard, cuyos "Lamentos estériles" fueron traducidos por César Nicolás Penson, también dominicano.

(5).-En el gran poeta colombiano José Asunción Silva podemos encontrar marcadas afinidades con Poe. Baste recordar "que Silva logró algunos efectos de musicalidad tan felices como los que Poe alcanzó a producir en "Las campanas".

(6).--Menéndez Pelayo anotó, en carta dirigida a un traductor dominicano de Manzoni, César Nicolás Penson, unas diez o doce versiones de "El cinco de mayo". Hay otra traducción de un dominicano, José Francisco Pichardo, que no se ajusta al metro de Manzoni.

(7).-Paralelamente, la influencia del realismo francés se hizo patente en la novela hispanoamericana, alternando con la de algunos novelistas españoles. He tratado someramente el asunto en $E l$ retorno de los galeones. 
(8).-Es curioso señalar también la influencia de Louis Bouilhet. Una de las composiciones más conocidas de Gutiérrez Nájera, "Para un menú", que termina:

Dejemos las copas... Si queda una gota, ique beba el lacayo las beces de amor!,

no es más que una paráfrasis de unos versos de Bouilhet, que a su vez terminan de esta suerte:

Le banquet est fini.

Quand j'ai vidé ma tasse

S'il reste encore $d u$ vin,

Les laquais le boiront...

No es ocioso recordar que otro de los fundadores del modernismo, el cubano Julián del Casal, tradujo una poesía de Bouilhet.

(9).-El Maestro Sanín Cano me aporta en una carta el dato de que Silva imitó en algunas "gotas amargas" a Josepin Soulary. Y agrega: "«Un Poema» es de factura parnasiana. En Bogotá fueron conocidos los poetas del Parnaso y muchos más modernos franceses por el amor con que Silva difundía sus obras y recitaba sus versos". Y por último añade esta interesante observación: "Del influjo de la poesía francesa sobre Silva nació en éste su fervoroso cultivo del eneasílabo, en el cual dejó poesías de mérito superior... Después de Silva, los modernos se encariñaron de tal medida, como del alejandrino, aunque con menos empeño, porque el eneasílabo es más difícil y tiene sonoridades recónditas no de todos captables".

(10).-Arciniegas fué, además, un traductor múltiple. Vertió al castellano un gran número de composiciones de poetas franceses del siglo XIX, empezando por los románticos, pasando por los parnasianos, después por los simbolistas, y acabando por algunos de la hora actual. Raro es el poeta francés, de alguna significación, del cual Arciniegas no haya traducido siquiera una o dos composiciones. Uno de sus últimos empeños, poco antes de morir, fué la traducción integral de T $u$ y yo, de Paul Géraldy, que también ha sido traducido por el centroamericano Roberto Brenes Mesén.

(11).-Londoño es uno de los que con más justicia merecen en la América Española el dictado de parnasianos. Su soneto "El último centauro" es digno del autor de Los trofeos. Ese soneto se publicó con la explicación de que el autor se había inspirado en un soneto inédito de Heredia: la publicación de los manuscritos de Heredia en Le Manuscrit Autographe (París, 1929-1930) demuestra que Heredia no tenía ningún soneto inédito que corresponda en alguna forma al de Londoño, lo cual demuestra que Londoño sólo tuvo presentes los sonetos de la serie "Hércules y los centauros". Londoño también publicó pulcras traducciones de 
Sully Prudhomme, Verlaine, Heredia, Fernando Gregh, Charles Guerin, Laforgue, Paul Fort, y otros.

(12).-Tanto Dávalos como González Martínez han recogido en volumen sus traducciones de muchos poetas franceses, principalmente contemporáneos.

(13).-De Francis Jammes hay algunas traducciones atinadas, como las del peruano Manuel Beltroy.

(14).-Véase también el interesante estudio de Isaac J. Barrera: "A1bert Samain y su influencia en la literatura ecuatoriana" (1930). 
